\title{
PERFORMANCE BASED CLUSTERING FOR BENCHMARKING OF CONTAINER PORTS: AN APPLICATION OF DEA AND \\ CLUSTER ANALYSIS TECHNIQUE
}

\author{
Jie $\mathbf{W u}^{1,{ }^{*}}$, Liang Liang ${ }^{1}$, Malin Song ${ }^{1}$ \\ ${ }^{1}$ School of Management \\ University of Science and Technology of China \\ He Fei, An Hui Province, P.R. China 230026 \\ Received: 07-12-2009 \\ Accepted: 16-09-2010
}

Email: jacky012@mail.ustc.edu.cn; lliang@ustc.edu.cn; malinsong@gmail.com

\begin{abstract}
The operational performance of container ports has received more and more attentions in both academic and practitioner circles, the performance evaluation and process improvement of container ports have also been the focus of several studies. In this paper, Data Envelopment Analysis (DEA), an effective tool for relative efficiency assessment, is utilized for measuring the performances and benchmarking of the 77 world container ports in 2007. The used approaches in the current study consider four inputs (Capacity of Cargo Handling Machines, Number of Berths, Terminal Area and Storage Capacity) and a single output (Container Throughput). The results for the efficiency scores are analyzed, and a unique ordering of the ports based on average cross efficiency is provided, also cluster analysis technique is used to select the more appropriate targets for poorly performing ports to use as benchmarks.

Keywords: Decision support systems; Data envelopment analysis; Performance measurement; Machine learning; Benchmarking; Container ports
\end{abstract}

\footnotetext{
${ }^{*}$ School of Management, University of Science and Technology of China, He Fei, An Hui Province 230026, China
} 


\section{Introduction}

Due to the advanced technology and economy of scale in the container transportation operations, the operations efficiency of a container port becomes critically important impacting the overall efficiency of the global logistics network. On the other hand, along with the fast development in the port industry and more efficiently integrated transportation network, the numbers of container ports in those hot economy regions are clearly increased in the recent years, and these ports all face an ever competitive market. Therefore, the proper and precise evaluation of container port performance not only helps a port understand and improve its marketing and competitive position, but also provide a clear and solid base for the local government policy maker for the long term development.

DEA (Data Envelopment Analysis) is a fractional programming model that evaluates the relative efficiency of homogeneous units in the presence of multiple inputs and outputs. The efficiency is defined as the ratio of the weighted sum of outputs to a weighted sum of inputs. DEA has been primarily used to compare the efficiencies of a homogeneous set of decision making units (DMUs) such as schools, hospitals, airlines, manufacturing companies, shops, bank branches, project selection and other environments (Pahlavani, 2010; Lopez et al, 2010; Doreswamy, 2010; Xu et al, 2009; Liu et al, 2008; Gürbüz, 2010; Kaya, 2010 and Zhao et al, 2010).

It has been found in the literature that DEA method (Charnes, Cooper and Rhodes, 1978) forms a main stream in the container port performance evaluation. Different version of DEA models are applied for various container port evaluations. Roll and Hayuth (1993) use a $\mathrm{CCR}^{1}$ DEA model to theoretically rate the efficiency of ports, and 20 container ports with 3 inputs and 4 outputs are evaluated. Martinez-Budria et al (1999) develop a $\mathrm{BCC}^{2}$ model to examine the relative efficiency of 26 Spanish ports using input and output data during year 1993 to 1997. Tongzon (2001) applies an additive CCR DEA model to empirically test the various factors influencing the efficiency of a

\footnotetext{
1 The model proposed in Charnes, Cooper and Rhodes (1978), and named by the first words of these three scholars. 2 The model proposed in Banker, Charnes and Cooper (1984), and named by the first words of these three scholars.
}

port. Valentine and Gray (2001) again use a CCR DEA model to compare the efficiency of 31 world top container ports with different ownerships and organizational structures. Cullinane and Wang (2005) investigate the relationship between the privatization and DEA efficiency. Other DEA based international container port performance evaluations can be found in Cullinane et al (2004), Cullinane and Wang (2006), Cullinane et al (2005), Cullinane et al (2006), Park and De (2004), Turner et al (2004). There are also DEA based researches concerning the port performance of specified countries, including that Barros (2003a, 2003b) analyzes the incentive regulation, seaport authorities in Portuguese seaports. Barros and Athanassiou (2004) compare the efficiency from the seaports from Greece and Portugal. Bonilla et al (2004) analyze the efficiency of Spanish port system. Itoh (2002) uses the window DEA model to view the efficiency changes at major Japanese container ports. Martinez Budria et al (1999) study the DEA efficiency of port authorities in Spain.

From the review of above literatures, we can find the operational performances of container ports using DEA have received significant attentions in the literature. However, relatively few academic studies have investigated the complete ranking of container ports and the benchmarking analysis of container ports, which have important implications for the managers of container ports and others.

In this paper, we implement the cross efficiency evaluation method to assess the performance efficiency of 77 world container ports in different countries. Four popular performance measures for the evaluation of container ports, Capacity of Cargo Handling Machines, Number of Berths, Terminal Area and Storage Capacity, are used as the input indexes, one single performance measure, Container Throughput, is considered as the output index. By implementing this DEA analysis, we can calculate the cross-efficiency to provide a unique ordering of the container ports. Using the cluster analysis, we select the more appropriate targets for poorly performing ports to use as benchmarks. An advantage of cross-efficiency over simple efficiency is that the former can be used to rank all DMUs and Doyle and Green (1994) argued that cross efficiency evaluation method is more general, and more powerful than 
traditional ranking method based on DEA, such as the reference-set count. Cluster analysis is used for identifying benchmarks for poorly performing container ports. Container ports which are inherently similar with respect to their inputs and outputs are classified into the same cluster. The port with the highest score in a given cluster can be used as the primary benchmark for improvement by other ports in that cluster. Besides, some insightful management information on container ports are also revealed.

The rest of this paper is organized as follows. Section 2 gives a brief review of the relevant DEA models. Data descriptions are made in Section 3. Section 4 conducts the numerical testing and analysis. Section 5 draws conclusions and final remarks.

\section{Methodology}

In this section, we will provide a brief review of the basic DEA model, cross efficiency DEA model and the benchmarking method based on cluster analysis technique and DEA.

\subsection{Cross efficiency}

The cross-evaluation method was developed as a DEA extension tool that can be utilized to identify best performing DMUs and to rank DMUs, its main idea is to use DEA in a peer evaluation instead of a self-evaluation mode. Cross efficiency evaluation has been used in various applications, e.g., efficiency evaluations of nursing homes (Sexton et al.1986), R\&D project selection (Oral, Kettani and Lang, 1991), preference voting (Green, Doyle and Cook, 1996), and others.

Adopting the conventional nomenclature of DEA, assume that there are $\mathrm{n}$ DMUs that are to be evaluated in terms of $\mathrm{m}$ inputs and $\mathrm{s}$ outputs. We denote the ith input and rth output for
$D M U_{j}(j=1, \ldots, n)$ as $x_{i j}(i=1, \ldots, m)$ and $y_{r j}$ $(r=1, \ldots, s)$, respectively. The efficiency rating for any given $D M U_{d}$, can be computed using the following CCR model proposed by Charnes, Cooper and Rhodes (1978).

$$
\begin{aligned}
\max & \sum_{r=1}^{s} \mu_{r d} y_{r d} \\
\text { s.t. } & \sum_{i=1}^{m} \omega_{i d} x_{i j}-\sum_{r=1}^{s} \mu_{r d} y_{r j} \geq 0, j=1,2, \ldots n \\
& \sum_{i=1}^{m} \omega_{i d} x_{i d}=1 \\
& \omega_{i d} \geq 0, i=1,2, \ldots ., m \\
& \mu_{r d} \geq 0, r=1,2, \ldots, s
\end{aligned}
$$

where $d$ is the DMU being evaluated, $\omega_{i d}$ is the weight given to input $i$, and $\mu_{r d}$ is the weight given to output $r$.

For each $D M U_{d}(d=1, \ldots, n) \quad$ under evaluation, we obtain a set of optimal weights (multipliers) $\omega_{1 d}^{*}, \ldots, \omega_{m d}^{*}, \mu_{1 d}^{*}, \ldots, \mu_{s d}^{*}$. Using this set, the $d$-cross efficiency for any $D M U_{j}(j=1, \ldots, n)$, is then calculated as:

$$
E_{d j}=\frac{\sum_{r=1}^{s} \mu_{r d}^{*} y_{r j}}{\sum_{i=1}^{m} \omega_{i d}^{*} x_{i j}}, d, j=1,2, \ldots, n
$$

As shown in Table 1, when we move along the dth row of the matrix $\mathrm{E}$ of cross efficiencies, each element $E_{d j}$ is the efficiency that $D M U_{d}$ accords to $D M U_{j}$, given the computed weighting scheme described above. The leading diagonal is the special case where $D M U_{d}$ rates itself. 
Table 1. A generalized cross efficiency matrix (CEM)

\begin{tabular}{cccccc}
\hline Rating DMU & \multicolumn{5}{c}{ Rated DMU } \\
\cline { 2 - 6 } 1 & 1 & 2 & 3 & $\ldots$ & $\mathrm{n}$ \\
2 & $E_{11}$ & $E_{12}$ & $E_{13}$ & $\ldots$ & $E_{1 n}$ \\
3 & $E_{21}$ & $E_{22}$ & $E_{23}$ & $\ldots$ & $E_{2 n}$ \\
$\cdot$ & $E_{31}$ & $E_{32}$ & $E_{33}$ & $\ldots$ & $E_{3 n}$ \\
$\cdot$ & $\cdot$ & $\cdot$ & $\cdot$ &. \\
$\mathrm{n}$ & $\cdot$ & $\cdot$ & $\cdot$ & $\cdot$ & $\cdot$ \\
Mean & $\cdot$ & $\cdot$ & $E_{n 2}$ & $\ldots$ & $\cdot$ \\
& $E_{n 1}$ & $\bar{E}_{2}$ & $\bar{E}_{33}$ & $\ldots$ & $\bar{E}_{n}$ \\
\hline
\end{tabular}

Each of the columns of the CEM in Table 1 is then averaged to get a mean cross efficiency measure for each DMU. For $D M U_{j}(j=1, \ldots, n)$, the average of all $E_{d j}(d=1, \ldots, n)$, namely

$$
\overline{E_{j}}=\frac{1}{n} \sum_{d=1}^{n} E_{d j}
$$

can be used as a new efficiency measure for $D M U_{j}$, and will be referred to as the cross

efficiency score for $D M U_{j}$.

In general, the weights of input and output in model (1) may not be unique. Thus, a DMU's evaluation of other DMU's may depend on the first of the many alternate optimal solutions reached. To resolve choice amongst multiple solutions, Sexton et al. (1986) and Doyle and Green (1994) suggested the use of aggressive and benevolent cross-evaluation. A cross-evaluation is aggressive/benevolent in the sense that it selects a set of weights which not only maximize the efficiency of a particular DMU under evaluation, but also minimize/maximize the efficiencies of all other DMUs in some sense.

In situations where relative dominance among the DMUs is to be evaluated, the aggressive formulation is more appropriate (Talluri and Sarkis, 1997). The accordance aggressive formulation of (1) developed by Doyle and Green (1994) is shown as (4)

$$
\begin{array}{ll}
\min & \sum_{r=1}^{s} \mu_{r d}\left(\sum_{j=1, j \neq d}^{n} y_{r j}\right) \\
\text { s.t. } & \sum_{i=1}^{m} \omega_{i d} x_{i j}-\sum_{r=1}^{s} \mu_{r d} y_{r j} \geq 0, j=1, \ldots, n . \\
& \sum_{i=1}^{m} \omega_{i d}\left(\sum_{j=1, j \neq d}^{n} x_{i j}\right)=1, \\
& \sum_{r=1}^{s} \mu_{r d} y_{r d}-E_{d d} \sum_{i=1}^{m} \omega_{i d} x_{i d}=0 \\
& \omega_{i d} \geq 0, i=1, \ldots, m . \\
& \mu_{r d} \geq 0, r=1, \ldots, s .
\end{array}
$$

where $E_{d d}$ is the efficiency of $D M U_{d}$ obtained from (1).

The benevolent formulation has the same set of constraints except that the objective function is maximized.

\subsection{Benchmarking}

In DEA, a linear combination of DMU's in the reference set is the target that an inefficient DMU uses to become efficient. According to Doyle and Green (1994), a difficulty with these conventional reference sets is that an inefficient DMU and its reference sets may not be inherently similar in their practices. Therefore, it is possible that these reference targets are unattainable goals for the inefficient DMU's. Literature has suggested using cluster analysis, principal components, and multidimensional scaling to classify DMU's more accurately into similar groups or clusters. 
Cluster analysis is used in this methodology for identifying benchmarks for poorly performing DMU's. Computing the correlation coefficient between pairs of columns in a CEM tells us how similarly those DMU's are appraised by their peers. A high positive correlation coefficient indicates that the two DMU's are inherently similar with respect to their inputs and outputs. This means that these DMU's are performing similarly when evaluated with the optimal weights of other DMU's. Thus, using these correlation coefficients as the elements in a resemblance matrix and executing a clustering method yields clusters with inherently similar DMU's. The DMU with the highest column mean in a given cluster can be used as the primary benchmark for improvement by other DMU's in that cluster.

\section{Data descriptions}

The data utilized for the study is derived from two major sources, the relevant issues of the Containerization International Yearbook and two mail surveys sent to selected container ports. Considered the data availability and the usable responses of the selected ports, the sample comprises 56 world's leading container ports in 2007. As some container ports include more than one container terminal (e.g., the Osaka container port of Japan includes Omni Terminal, Osaka Port, OsakaTC1, OsakaTC2, OsakaTC8 and OsakaTC9), the sample for analysis comprises a total size of 77; either container ports or individual terminals within container ports. The ports sample includes 18 ports from Asia (28 terminal operators), 15 ports from Europe (22 terminal operators), 10 ports from North America (12 terminal operators), 6 ports from Latin America ( 7 terminal operators), 4 ports from Africa (4 terminal operators) and 3 ports from Oceania (4 terminal operators) (the detail is included in Appendix).

The input and output variables should reflect actual objectives and the process of container port production as accurately as possible. As far as the former objective is concerned (Cullinane et al., 2004), the observed performance of a port need to be closely related to its objectives. Considering the variables in the prior studies, experts' suggestion and the main objective of this paper, we choose the variables listed in Table 2 for analysis. The required data are mainly taken from relevant issues of the Containerization International Yearbook. Important statistics relating to the sample are summarized in Table 3.

Table 2. List of Variables

\begin{tabular}{cccccc}
\hline & \multicolumn{3}{c}{ Input } & Output \\
\hline Variable & Capacity of Cargo & Number of & Terminal & Storage & Container Throughput \\
name & Handling Machines & Berths & Area & Capacity & (TEUs) \\
Symbol & $X_{1}$ & $X_{2}$ & $X_{3}$ & $X_{4}$ & $Y$ \\
& Unitage & Unitage & M square & TEU & TEU \\
\hline
\end{tabular}

Table 3. Statistical properties of the dataset

\begin{tabular}{cccccc}
\hline & $X_{1}$ & $X_{2}$ & $X_{3}$ & $X_{4}$ & $Y$ \\
\hline Min & 216.21 & 1 & 28000 & 560 & 12966 \\
Max & 48701 & 24 & 8092000 & 180000 & 5258000 \\
Mean & 5095.005 & 4.805195 & 680009.4 & 20091.47 & 887727.8 \\
Std. Dev & 6842.834 & 4.279815 & 1107563 & 27617.72 & 946047.2 \\
\hline
\end{tabular}

\section{Results and discussions}

In section 2 , we have presented cross efficiency evaluation method used to analyze the performance of container ports. In this section, we apply cross efficiency evaluation method to 
analyze the performance of 77 world container ports in 2007. The performance evaluation of ports is assessed by the aggressive formulation (4) proposed by Doyle and Green (1994).

\subsection{Efficiency analysis}

Table 4 shows, for each container port, its efficiency in model (1), average cross efficiency and two ranking results based on these two efficiency scores. It can be seen that a total of ten ports (13\% of the sample) are considered to be efficient and are on the performance frontier in 2007.

The average cross-efficiency score and its ranking are shown in the last two columns of Table 4, which indicates that Shekou Port (DMU 14 , efficient port) has the highest score of 0.92 , and is rated as the port with the best performance by the other ports. Puerto Limon Port (DMU 16), which is shown to be efficient by the analysis of model (1), achieves a score of 0.8444 and is ranked second in the entire set. If we utilize the average cross efficiency to rank these 77 container ports, except for the two ports (DMU 14 and DMU 16) mentioned above, Freeport (DMU 7, 0.8094) is ranked the third place, followed by North Sea Terminal (DMU 20, 0.7939), LYC Dock (DMU 60, 0.7847), Manzanillo Port (DMU 48, 0.7759) and so on. Although LYC Dock (DMU 60, 0.7847) and Manzanillo Port (DMU 48, 0.7759) are considered as inefficient ports by efficiency in model (1), they achieved rather high average cross efficiency, so they are ranked fifth and sixth, respectively, and have better overall performance than some other efficient container ports which are considered by the evaluation of model (1).

Table 4. Performance evaluation results of container ports

\begin{tabular}{|c|c|c|c|c|c|c|c|}
\hline Country & Port & $\begin{array}{c}\text { Port/Terminal } \\
\text { Operator }\end{array}$ & $\begin{array}{l}\text { DMU } \\
\text { No. }\end{array}$ & $\begin{array}{c}\text { CCR } \\
\text { efficiency }\end{array}$ & Ranking & $\begin{array}{l}\text { Aggressive } \\
\text { cross } \\
\text { efficiency }\end{array}$ & Ranking \\
\hline \multirow[t]{4}{*}{ Argentina } & Buenos Aires & Buenos Aires & 1 & & 36 & & 42 \\
\hline & & Terminal 123 & & 0.5087 & & 0.3203 & \\
\hline & & Buenos Aires & 2 & & 70 & & 68 \\
\hline & & Terminal 5 & & 0.1442 & & 0.1078 & \\
\hline \multirow[t]{6}{*}{ Australia } & Brisbane & Brisbane Berth 456 & 3 & 0.3827 & 47 & 0.2906 & 45 \\
\hline & Melbourne & Melbourne P\&O & 4 & & 29 & & 25 \\
\hline & & Berth 1-4 & & 0.6518 & & 0.4954 & \\
\hline & & Melbourne Patrick & 5 & & 11 & & 9 \\
\hline & & Stevedores Berth 1-4 & & 0.9698 & & 0.7021 & \\
\hline & Sydney & Northern Terminal & 6 & 0.3513 & 51 & 0.2835 & 47 \\
\hline Bahamas & Freeport & Freeport & 7 & 1 & 1 & 0.8094 & 3 \\
\hline Belgium & Zeebregge & OCHZ Terminal & 8 & 0.3553 & 50 & 0.2415 & 51 \\
\hline Brazil & Santos & Terminal 37 & 9 & 0.467 & 40 & 0.3338 & 39 \\
\hline \multirow[t]{4}{*}{ Canada } & Vancouver & $\begin{array}{l}\text { Centren Terminal } \\
\text { (Casco P\&O \& Port }\end{array}$ & 10 & & 67 & & 67 \\
\hline & & Canada) & & 0.19 & & 0.1352 & \\
\hline & & Deltaport & 11 & 0.6127 & 30 & 0.5024 & 24 \\
\hline & & Vanterm & 12 & 0.2927 & 55 & 0.2312 & 53 \\
\hline \multirow[t]{3}{*}{ China } & Qingdao & Qingdao Port & 13 & 1 & 1 & 0.6026 & 14 \\
\hline & Shenzhen & Shekou Port & 14 & 1 & 1 & 0.92 & 1 \\
\hline & & Yantian Port & 15 & 0.7878 & 22 & 0.7072 & 8 \\
\hline Costa Rica & Puerto Limon & Puerto Limon Port & 16 & 1 & 1 & 0.8444 & 2 \\
\hline Coted & Abidjan & Abidjan Port & 17 & 0.7967 & 20 & 0.6285 & 12 \\
\hline
\end{tabular}




\begin{tabular}{|c|c|c|c|c|c|c|c|}
\hline Ivoire & & & & & & & \\
\hline Egypt & Damietta & Damietta Port & 18 & 0.3074 & 53 & 0.2583 & 50 \\
\hline \multirow[t]{2}{*}{ France } & Le Harve & Terminal de le & 19 & & 73 & & 71 \\
\hline & & Atlantique & & 0.0999 & & 0.08 & \\
\hline \multirow[t]{5}{*}{ Germany } & Bremen & North Sea Terminal & 20 & 1 & 1 & 0.7939 & 4 \\
\hline & Hamburg & Burchardkai Terminal & 21 & 0.8905 & 15 & 0.6438 & 11 \\
\hline & & Tollerort Terminal & 22 & 0.5313 & 32 & 0.4148 & 29 \\
\hline & & hEurogate Container & 23 & & 44 & & 41 \\
\hline & & Terminal & & 0.4396 & & 0.3268 & \\
\hline Greece & Piraeus & Piraeus Port & 24 & 0.5166 & 34 & 0.3941 & 33 \\
\hline Hong & Hong Kong & Modern Terminal & 25 & & 17 & & 10 \\
\hline Kong & & & & 0.8732 & & 0.6973 & \\
\hline \multirow[t]{2}{*}{ India } & Jawaharlal & NSICT & 26 & & 1 & & 15 \\
\hline & Nehru & & & 1 & & 0.5969 & \\
\hline Israel & Haifa & Haifa Port & 27 & 0.9616 & 12 & 0.5628 & 18 \\
\hline \multirow[t]{6}{*}{ Italy } & Genoa & Messina Terminal & 28 & 0.342 & 52 & 0.2298 & 54 \\
\hline & & SECH Terminal & 29 & 0.4474 & 43 & 0.2382 & 52 \\
\hline & & Voltri Terminal & 30 & 1 & 1 & 0.7177 & 7 \\
\hline & Leghorn & Darsena Toscana & 31 & & 57 & & 74 \\
\hline & & Terminal & & 0.2727 & & 0.0648 & \\
\hline & & Sintermar Terminal & 32 & 0.0954 & 74 & 0.0746 & 73 \\
\hline \multirow[t]{2}{*}{ Jamaica } & Kingston & Kingston Container & 33 & & 39 & & 37 \\
\hline & & Terminal APM & & 0.4689 & & 0.3641 & \\
\hline \multirow[t]{13}{*}{ Japan } & Kobe & Kobe PC $14 \& 15$ & 34 & 0.2659 & 58 & 0.2232 & 56 \\
\hline & Nagoya & Kinjo Pier & 35 & 0.027 & 76 & 0.0193 & 77 \\
\hline & & NCB Terminal of & 36 & & 33 & & 28 \\
\hline & & Nagoya Terminal & & & & & \\
\hline & & Service Center & & 0.5292 & & 0.4241 & \\
\hline & & Nebeta (ITS)\&ITS & 37 & & 1 & & 19 \\
\hline & & Co Ltd & & 1 & & 0.5542 & \\
\hline & Osaka & Omni Terminal & 38 & 0.6532 & 27 & 0.4425 & 26 \\
\hline & & Osaka Port & 39 & 0.6532 & 27 & 0.4425 & 26 \\
\hline & & OsakaTC1 & 40 & 0.2502 & 60 & 0.2071 & 58 \\
\hline & & OsakaTC2 & 41 & 0.2119 & 66 & 0.182 & 62 \\
\hline & & OsakaTC8 & 42 & 0.2413 & 62 & 0.1871 & 61 \\
\hline & & OsakaTC9 & 43 & 0.5094 & 35 & 0.3876 & 35 \\
\hline \multirow[t]{4}{*}{ Korea } & Busan & U_AM_Container & 44 & & 41 & & 34 \\
\hline & & Terminal & & 0.4639 & & 0.3929 & \\
\hline & Gwangyang & Global Gwangyang & 45 & & 69 & & 69 \\
\hline & & Terminal & & 0.1462 & & 0.0983 & \\
\hline \multirow[t]{3}{*}{ Malaysia } & Pasir Gudang & Pasir Gudang Port & 46 & 0.8081 & 18 & 0.568 & 17 \\
\hline & Tanjung & Tanjung Pelepas Port & 47 & & 13 & & 20 \\
\hline & Pelepas & & & 0.9528 & & 0.5356 & \\
\hline Mexico & Manzanillo & Manzanillo Port & 48 & 0.9519 & 14 & 0.7759 & 6 \\
\hline
\end{tabular}




\begin{tabular}{|c|c|c|c|c|c|c|c|}
\hline & Puerto & Puerto Manzanillo & 49 & & 25 & & 32 \\
\hline & Manzanillo & Port & & 0.7373 & & 0.4014 & \\
\hline Oman & Salalah & Salalah Port & 50 & 0.6549 & 26 & 0.3125 & 43 \\
\hline \multirow[t]{3}{*}{ Philippines } & Manila & Manila International & 51 & & 54 & & 55 \\
\hline & & Container Terminal & & 0.3028 & & 0.2234 & \\
\hline & & South Harbor & 52 & 0.2385 & 64 & 0.1566 & 65 \\
\hline \multirow[t]{6}{*}{ Portugal } & Lisbon & Santa Apolonia & 53 & & 65 & & 63 \\
\hline & & Container Terminal & & 0.2288 & & 0.1803 & \\
\hline & & Santos Quay & 54 & & 37 & & 38 \\
\hline & & (Terminal & & & & & \\
\hline & & Multipurpose De & & & & & \\
\hline & & Lisbon) & & 0.48 & & 0.3355 & \\
\hline \multirow[t]{2}{*}{ Russia } & St Petersburg & Fist Container & 55 & & 46 & & 48 \\
\hline & & Terminal & & 0.3857 & & 0.281 & \\
\hline Saudi & Dammam & Container Terminal & 56 & 0.3708 & 48 & 0.2849 & 46 \\
\hline \multirow[t]{4}{*}{ Arabia } & Jeddah & Northern Container & 57 & & 68 & & 66 \\
\hline & & Terminal & & 0.1753 & & 0.1394 & \\
\hline & & Southern Container & 58 & & 61 & & 59 \\
\hline & & Terminal & & 0.2446 & & 0.1929 & \\
\hline South & Durban & Durban Port & 59 & & 31 & & 30 \\
\hline Africa & & & & 0.5598 & & 0.4108 & \\
\hline \multirow[t]{5}{*}{ Spain } & Las Palmas De & LYC Dock & 60 & 0.8823 & 16 & 0.7847 & 5 \\
\hline & Gran Canaria & La Luz Container & 61 & & 49 & & 49 \\
\hline & & Terminal & & 0.3629 & & 0.2753 & \\
\hline & Valencia & Maritima Valenciana & 62 & & 1 & & 21 \\
\hline & & SA & & 1 & & 0.5229 & \\
\hline \multirow[t]{2}{*}{ Sri Lanka } & Colombo & SAGT Container & 63 & & 42 & & 40 \\
\hline & & Terminal & & 0.4553 & & 0.3276 & \\
\hline Sweden & Gothenburg & Gothenburg Port & 64 & 0.1051 & 72 & 0.0772 & 72 \\
\hline \multirow[t]{3}{*}{ Thailand } & Laem Chabang & LCB1 Terminal & 65 & & 21 & & 23 \\
\hline & & B1\&LCB Container & & & & & \\
\hline & & Terminal $1 \mathrm{Ltd}$ & & 0.79 & & 0.5051 & \\
\hline \multirow[t]{2}{*}{ UK } & Felixstowe & Felixstowe Port & 66 & 0.241 & 63 & 0.1784 & 64 \\
\hline & Southampton & Southampton Port & 67 & 0.478 & 38 & 0.4104 & 31 \\
\hline \multirow[t]{10}{*}{ USA } & Boston & Boston Port & 68 & 0.1128 & 71 & 0.0855 & 70 \\
\hline & Charleston & Charleston Port & 69 & 0.7523 & 23 & 0.5146 & 22 \\
\hline & Jacksonville & Jacksonville Port & 70 & 0.8019 & 19 & 0.5776 & 16 \\
\hline & Miami & Miami Port & 71 & 1 & 1 & 0.6258 & 13 \\
\hline & San Francisco & San Francisco Port & 72 & 0.0268 & 77 & 0.0198 & 76 \\
\hline & Savannah & Savannah Port & 73 & 0.7413 & 24 & 0.3861 & 36 \\
\hline & Long Beach & Long Beach & 74 & & 59 & & 57 \\
\hline & & Container Terminal & & 0.2516 & & 0.2169 & \\
\hline & New Orleans & Berth5\&6(Nomc & 75 & & 75 & & 75 \\
\hline & & Terminal) & & 0.073 & & 0.0613 & \\
\hline
\end{tabular}




\begin{tabular}{|c|c|c|c|c|c|c|c|}
\hline & New York & Port Newark & 76 & & 56 & & 60 \\
\hline & & Container Terminal & & 0.2737 & & 0.1923 & \\
\hline \multirow[t]{2}{*}{ Vietnam } & Ho Chi Minh & VI Container & 77 & & 45 & & 44 \\
\hline & City & Terminal & & 0.4173 & & 0.3008 & \\
\hline
\end{tabular}

\subsection{Benchmarking analysis}

As discussed in the introduction, although traditional CCR model provides benchmarks for inefficient ports, it has certain limitations. The main issue is that an inefficient port and its benchmarks may not be inherently similar in their practices (Doyle and Green, 1994).

To identify proper benchmarks that can be used by poorly performance ports as a basis for improvement, we firstly compute the correlation coefficient between a pair of columns in cross-efficiency matrix, which can tell us how similarly those two DMUs were appraised by their peers. Then we use these correlation coefficients as the elements in a resemblance matrix and the clustering technique based on an average linkage method is executed. The tree is truncated to obtaining a reasonable level of clustering among the container ports.

The cluster analysis used in this paper is a hierarchical clustering technique and the average linkage method ${ }^{3}$ is utilized in deriving the clusters. Figure 1 illustrates the clusters that are identified from the above technique to 77 world container ports in 2007. The clusters are obtained by truncating the dendrogram at a rescaled distance measure of 5 on a scale of 0 25 , where 0 represents a correlation coefficient of $1.000^{4}$. Although the cutoff measure is arbitrarily selected for illustrative purposes in this paper, it basically depends on the similarity level demanded by the decision maker or the number of benchmarking partners that the decision maker seeks in a cluster. As we go from left to right in the dendrogram similarity decreases and dissimilarity increases, which

\footnotetext{
${ }^{3}$ In this method, the distance between two clusters is defined as the average distance between all possible pairs of points within the two clusters. In this way, an average distance is calculated and the two clusters with the smallest average distance between their points are merged at each step.

${ }^{4}$ SPSS defines a dendrogram as a visual representation of the steps in a hierarchical clustering solution that shows the clusters being combined and the values of the distance coefficients at each step. Connected vertical lines designate joined cases. The dendrogram rescales the actual distances to numbers between 0 and 25 , preserving the ratio of the distances between steps.
}

would mean that the benchmarks may not be appropriate as we move towards the right of the diagram.

Figure 1 illustrates a total of seven clusters A, $\mathrm{B}, \mathrm{C}, \mathrm{D}, \mathrm{E}, \mathrm{F}$ and $\mathrm{G}$ are identified in this analysis. The best performers in each of the clusters are utilized by other ports in those clusters as the primary benchmarks for improvement. For example, in cluster D, DMU 71 (Miami Port) with an average cross efficiency score of 0.6258 should be utilized by DMU 13 (Qingdao Port), DMU 37 (Nebeta (ITS) \& ITS Co Ltd) and DMU 73 (Savannah Port) as a benchmark for improvement. These ports should identify the operating practices of Miami Port and implement those practices in order to become more competitive.

It is evident that in some of these clusters, such as cluster $\mathrm{E}$, the benchmark port itself is not a very good performer. Although this is the case, it is still important for the ports in this cluster to utilize it as a potential benchmark because improvements have to be performed in an incremental manner by first achieving an attainable target before making radical improvement strides. It so happens that the ports in this cluster are relatively poor performers and the most appropriate benchmark for improving their current practices is DMU 65 (LCB1 Terminal B1\&LCB Container Terminal $1 \mathrm{Ltd})$.

Considering the continental factor, we can easily find that the poor-performing container ports always utilize the ports from other continent. For example, in cluster D, DMU 13 (Qingdao Port) from China of Asia should identify DMU 71 (Miami Port) from USA of North America as the benchmark for efficiency improvement, which shows that the trend of globalization has greatly influenced the operations of the container port industry, and the geographical restrictions have been greatly weakened. 


\section{A $\quad$ DMU $7=0.8094$}

$1,2,3,4,5,8,9,10,21,22,24,27,28$,

$30,33,35,38,39,52,54,55,59,61,64$,

$69,70,72,77$

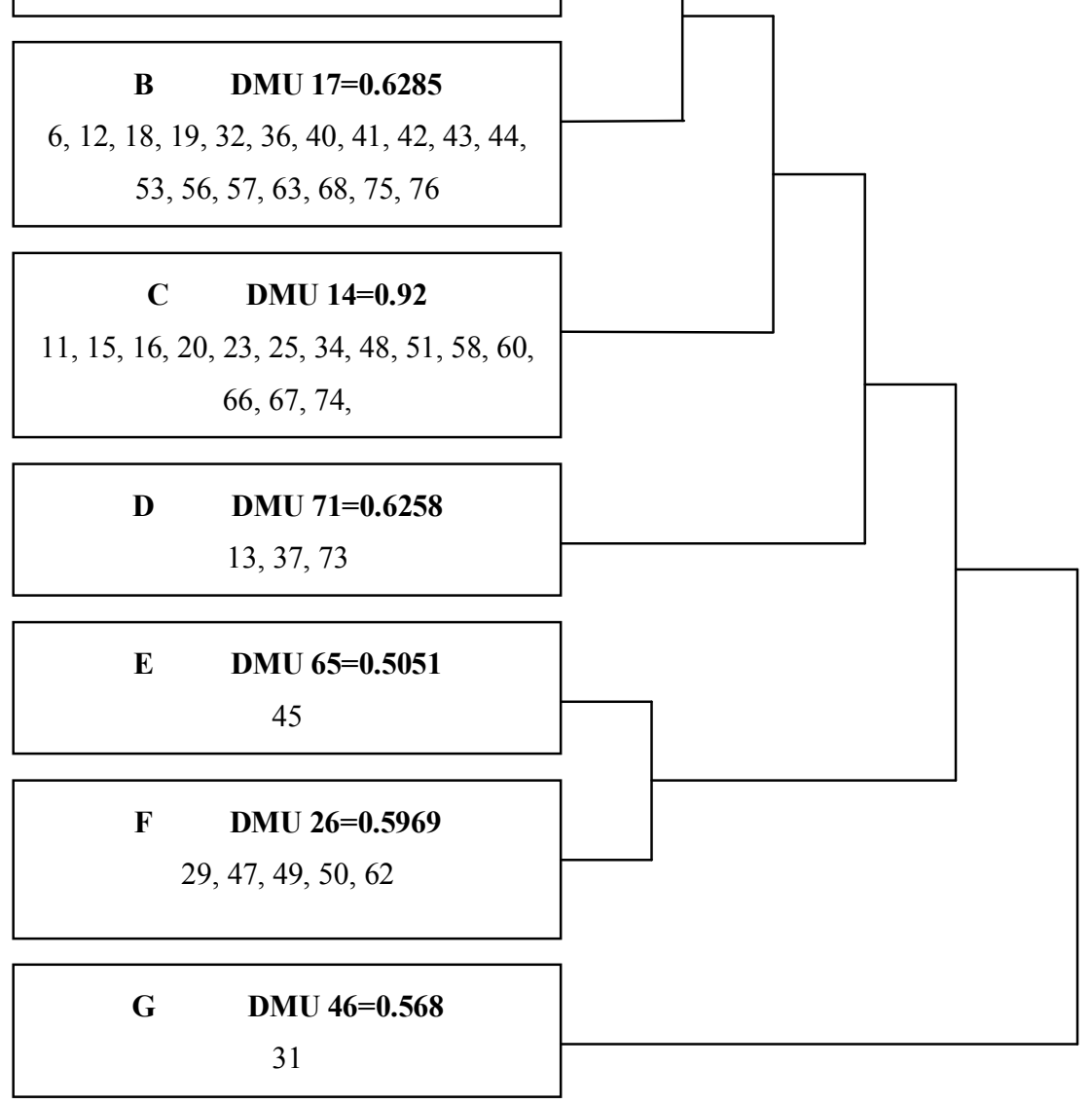

Fig. 1. Clustering result of container ports based on cross efficiency

\subsection{A Priori Clustering analysis}

As pointed out by one referee, it may be useful to carry out a priori clustering. That is, cluster all the 77 world container ports only on inputs, and to perform a priori clustering before the DEA efficiency analysis, the advantage of this method is that when units are clustered based on their inputs one can obtain homogenous groups of units with comparable resource levels.

For the purpose of comparison with the cluster results above, for the 4 -input and 1-output data set of 77 world container ports in 2007 , the same clustering technique is used to generate the homogenous groups of units, i.e., the cluster analysis used in this part is a hierarchical clustering technique and the average linkage method is utilized in deriving the clusters. Figure 2 illustrates the clusters that are identified from the above technique to 77 world container ports inputs and outputs data in 2007. Same to the treatments in section 4.2, the clusters are obtained by truncating the dendrogram at a rescaled distance measure of 5 on a scale of 0 25 , where 0 represents a correlation coefficient of 1.000 . 


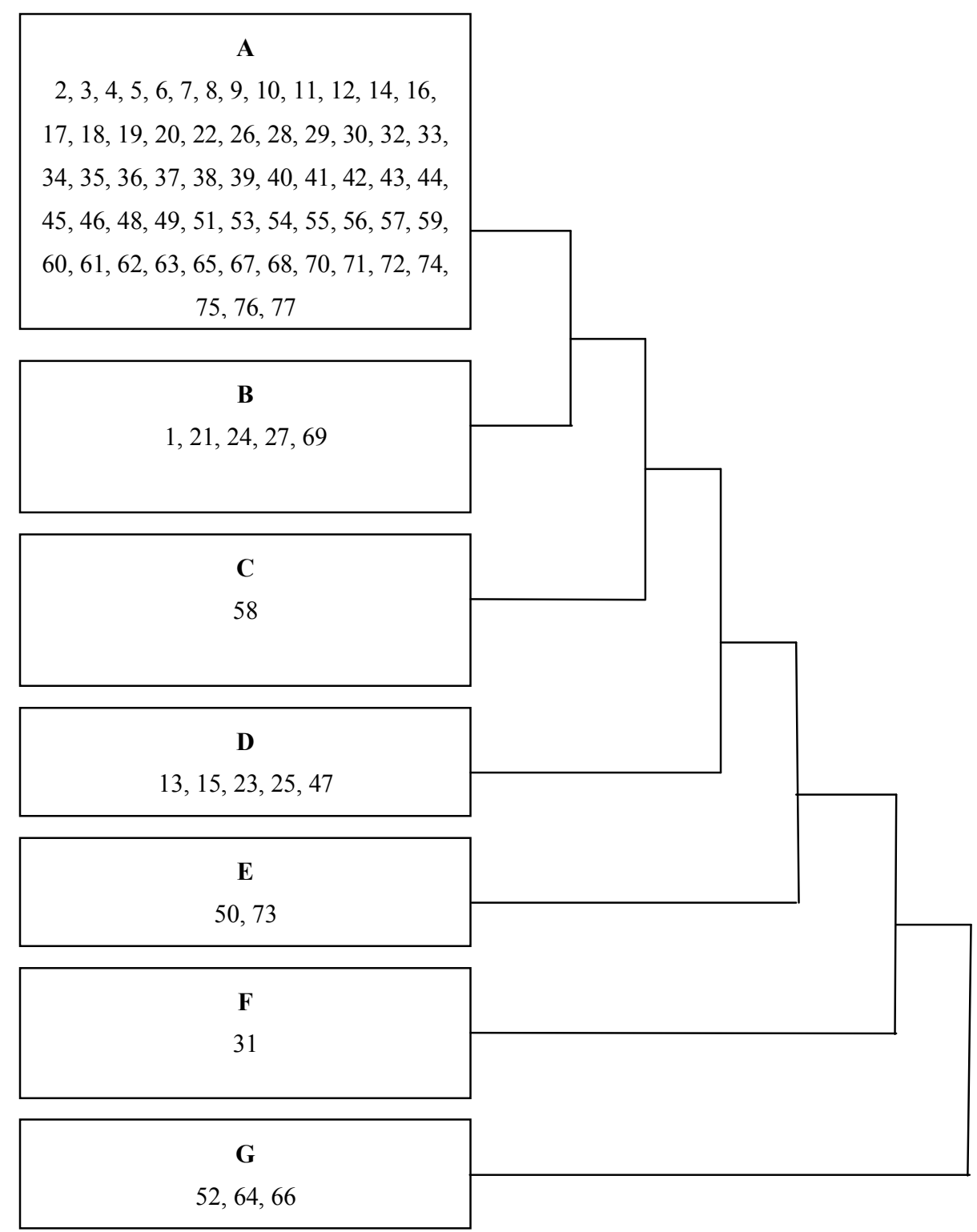

Fig. 2. Clustering result of container ports based on priori clustering analysis

Figure 2 illustrates a total of seven clusters A, $\mathrm{B}, \mathrm{C}, \mathrm{D}, \mathrm{E}, \mathrm{F}$ and $\mathrm{G}$ are identified in this analysis. The DMUs in one cluster indicates their structural similarity with regards to the levels of the inputs and outputs that DMUs receive and produce. For example, in cluster G, DMU 52 (South Harbor Port) from Philippines of Asia, DMU 64 (Gothenburg Port) from Sweden of Europe and DMU 66 (Felixstowe Port) from UK of Europe have the high 'structural similarity' of the inputs and outputs, and are classified into the same clusters.

It is noted that the results of our proposed model which are shown in Figure 1 are very different from the results of priori clustering depicted in Figure 2. For example, DMU 73 (Savannah Port) from USA is clustered with DMU 50 (Salalah Port) from Oman via priori clustering, while via the proposed approach in the current study, it is clustered with DMU 13 (Qingdao Port) from China, DMU 31 (Darsena Toscana Terminal Port) from Italy, and DMU 71 (Miami Port) from USA. Besides, the differences of the other DMUs between our proposed approach and the priori clustering can be also easily found after considering the results of Figure 1 and Figure 2. 


\section{Conclusions}

In this paper, we have demonstrated a methodology for performance evaluation and process improvement of 77 world container ports. We utilized a combination of multi-factor efficiency models, aggressive cross-efficiency DEA, and clustering methods for evaluating container port performance and in identifying appropriate benchmarks for improving poorly performing ports. Several important and interesting managerial insights were derived from this study. Managers and policy makers for improving the operational efficiencies of ports through benchmarking can utilize the methods in this paper.

As with any technique there are certain limitations to our models. One of the limitations of DEA is its sensitivity to data and parameter selection. If we had selected other parameters (inputs and outputs) or fewer parameters for evaluation, we may have obtained different outcomes. Even though this study provides a random sample of the full population, some extensions to overall industry competitiveness and efficiency may need to be evaluated further. Besides, investigating and evaluating various clustering approaches, factor analysis, and multi-dimensional scaling can all be avenues for future research.

\section{Acknowledgements}

The authors are grateful to the editors and anonymous referees for their insightful comments and helpful suggestions which helped to improve the previous version of this paper significantly. The research is supported by National Natural Science Funds of China for Innovative Research Groups (No. 70821001), National Natural Science Funds of China (No. 70901069), Special Fund for the Gainers of Excellent Ph.D's Dissertations and Dean's Scholarships of Chinese Academy of Sciences, Research Fund for the Doctoral Program of Higher Education of China for New Teachers (No. 20093402120013), Research Fund for the Excellent Youth Scholars of Higher School of Anhui Province of China (No. 2010SQRW001ZD) and Social Science Research Fund for Higher School of Anhui Province of China (No. 2010SK004).

\section{References}

1. C. P. Barros, Incentive regulation and efficiency of Portuguese port authorities, Marit. Ec. and Log. 5(1) (2003a) 55-69.

2. C. P. Barros, The measurement of efficiency of Portuguese seaport authorities with DEA, Int. J. of Transp. Ec. 30 (3) (2003b) 335-354.

3. C. P. Barros and M. Athanassiou, Efficiency in European seaports with DEA: Evidence from Greece and Portugal, Marit. Ec. and Log. 6 (2) (2004) 122-140.

4. M. Bonilla, T. Casasus, A. Medal and R. Sala, An efficiency analysis of the Spanish port system, Int. J. of Transp. Ec. 31 (3) (2004) 379-400,.

5. A. Charnes, W. W. Cooper and E. Rhodes, Measuring the efficiency of decision making units, Eur. J. of Oper. Res. 2 (6) (1978) 429-444.

6. D. A. Collier and J. E. Storbeck, A data envelopment approach to benchmarking in the telecommunications industry, Ohio State Faculty of Management Science Working Paper. Ohio State University, Columbus. (1993).

7. K. P. B. Cullinane, D. W. Song, P. Ji and T. F. Wang, An application of DEA windows analysis to container port production efficiency, Rev. Network Ec. 3 (2) (2004) 186-208.

8. K. P. B. Cullinane and T. F. Wang, The efficiency of European container ports: A cross-sectional data envelopment analysis, Int. J. of Log-Res. 9 (1) (2006) 19-31.

9. K. P. B. Cullinane, P. Ji and T. F. Wang, The relationship between privatization and DEA estimates of efficiency in the container port industry, J. of Ec, and Bus. 57 (5) (2005) 433-462.

10. K. P. B. Cullinane, T. F. Wang, D. W. Song and P. Ji, A comparative analysis of DEA and SFA approaches to estimating the technical efficiency of container ports, Transport. Res. A-Pol. 40 (5) (2005) 354-374.

11. K. P. B. Cullinane, D. W. Song and T. F. Wang, The application of mathematical programming approaches to estimating container port production, J. of Prod. Anal. 24 (1) (2005) 73-92.

12. H. Doreswamy and M. N. Vanajaskhi, Similarity Measuring Approach for Engineering Materials Selection, Int. J. Comput. System Sci. 3 (1) (2010) 115-122.

13. J. Doyle and R. Green, Efficiency and cross efficiency in DEA: Derivations, meanings and the uses, J. Oper. Res. Soc. 45 (5) (1994) 567-578.

14. R. Green, J. Doyle and W. D. Cook, Preference voting and project ranking using DEA and cross-evaluation, Eur. J. of Oper. Res. 90 (3) (1996) 461-472.

15. T. Gürbüz, Multiple criteria human performance evaluation using choquet integral, Int. J. Comput. System Sci. 3 (3) (2010) 290-300.

16. H. Itoh, Efficiency changes at major container ports in Japan: A window application of data 
envelopment analysis, Rev. of Urban and Regional Dev. Stud. 14 (2) (2002) 133-152.

17. T. Kaya, Multi-attribute evaluation of website quality in E-business using an integrated fuzzy AHPTOPSIS methodology, Int. J. Comput. System Sci. 3 (3) (2010) 301-314.

18. X. B. Liu, M. Zhou, J. B. Yang and S. L. Yang, Assessment of Strategic R\&D Projects for Car Manufacturers Based on the Evidential Reasoning Approach, Int. J. Comput. System Sci. 1 (1) (2008) 24-49.

19. V. Lopez, M. Santos and J. Montero, Fuzzy Specification in Real Estate Market Decision Making, Int. J. Comput. System Sci. 3 (1) (2010) 8-20.

20. B. E. Martinez, A. R. Diaz, I. M. Navarro and M. T. Ravelo, A study of the efficiency of Spanish port authorities using data envelopment analysis, Int. J. of Transp. Ec. 26 (2) (1999), 237-253.

21. M. Oral, O. Kettani and P. Lang, A methodology for collective evaluation and selection of industrial R\&D projects, Manage. Sci. 37 (7) (1991) 871-883.

22. A. Pahlavani, A new fuzzy MADM approach and its application to project selection, Int. J. Comput. System Sci. 3 (1) (2010) 103-114.

23. R. K. Park and P. De, An alternative approach to efficiency measurement of seaports, Marit. Ec. and Log. 6 (1) (2004) 53-69.

24. Y. Roll and Y. Hayuth, Port performance comparison applying data envelopment analysis (DEA), Marit. Pol. and Manage. 20 (2) (1993) 153-161.
25. T. R. Sexton, R. H. Silkman and A. J. Hogan, Data envelopment analysis: Critique and extensions, In: Silkman, R. H. (Ed.), Measuring Efficiency: An Assessment of Data Envelopment Analysis. Jossey-Bass, San Francisco, 32 (1986) 73-105.

26. S. Talluri and J. Sarkis, Extensions in efficiency measurement of alternate machine component grouping solutions via data envelopment analysis, IEEE T. Eng. Manage. 44 (3) (1997) 299-304.

27. J. Tongzon, Efficiency measurement of selected Australian and other international ports using data envelopment analysis, Transport. Res. A-Pol. 35 (2) (2001), 113-128

28. H. Turner, R. Windle and M. Dresner, North American container port productivity: 1984-1997, Transport. Res. E-Log. 40 (4) (2004) 339-356.

29. V. F. Valentine and R. Gray, The measurement of port efficiency using data envelopment analysis, Proceedings of the 9th world conference on transport research, 22-27 July, 2001. Seoul, Korea. (2001).

30. X. Xu, R. Law, T. Wu, Support Vector Machines with Manifold Learning and Probabilistic Space Projection for Tourist Expenditure Analysis, Int. J. Comput. System Sci. 2 (1) (2009) 17-26.

31. X. F. Zhao, H. J. Wang, G.W. Wei and R. Lin, Models for multiple attribute group decision making with 2-Tuple linguistic assessment information, Int. J. Comput. System Sci. 3 (3) (2010) 315-324.

Appendix A. Port list of each continent

\begin{tabular}{|c|c|c|c|c|c|}
\hline Asia & Europe & $\begin{array}{c}\text { North } \\
\text { America }\end{array}$ & Latin America & Africa & Oceania \\
\hline Qingdao & Zeebregge & Vancouver & Buenos Aires & Abidjan & Brisbane \\
\hline Shenzhen & Le Harve & Boston & Freeport & Damietta & Melbourne \\
\hline Hong Kong & Bremen & Charleston & Santos & Kingston & Sydney \\
\hline Jawaharlal Nehru & Hamburg & Jacksonville & Puerto Limon & Durban & \\
\hline Kobe & Piraeus & Miami & Manzanillo & & \\
\hline \multirow[t]{2}{*}{ Nagoya } & Haifa & San Francisco & Puerto & & \\
\hline & & & Manzanillo & & \\
\hline Osaka & Genoa & Savannah & & & \\
\hline Busan & Leghorn & Long Beach & & & \\
\hline Gwangyang & Lisbon & New Orleans & & & \\
\hline Pasir Gudang & St Petersburg & New York & & & \\
\hline \multirow[t]{2}{*}{ Tanjung Pelepas } & Las Palmas De Gran & & & & \\
\hline & Canaria & & & & \\
\hline Salalah & Valencia & & & & \\
\hline Manila & Gothenburg & & & & \\
\hline
\end{tabular}


Dammam

Jeddah

Colombo

Laem Chabang

Ho Chi Minh

City
Felixstowe

Southampton

Southampton

